\title{
Aging Time Effects on the Mechanical Properties of Al 6061-T6 Alloy
}

\author{
Shatha M. Rajaa \\ Institute of Technology \\ Baghdad, Iraq
}

\author{
Hassan A. Abdulhadi \\ Institute of Technology \\ Baghdad, Iraq
}

\author{
Khairallah S. Jabur \\ Institute of Technology \\ Baghdad, Iraq
}

\author{
Ghusoon R. Mohammed \\ Institute of Technology \\ Baghdad, Iraq
}

\begin{abstract}
This work investigates the influence of artificial aging and solution heat treatment on the hardness and tensile strength (mechanical properties) of Al 6061-T6 alloy. For this investigation, several aluminum 6061-T6 alloy specimens were prepared following the ASTM 176000 recommendations. The prepared specimens were heated for 1 hour at $500^{\circ} \mathrm{C}$ before being water-quenched. The procedure for artificial aging was performed for $1,2,3$, and 4 hours at $190^{\circ} \mathrm{C}$ before being slowly cooled in air. Several mechanical and characterization studies were performed on the treated specimens, including an investigation on their microstructure, tensile strength, hardness, and $X$-ray diffraction pattern. From the results, the strength and hardness properties of the specimens were found to be generally improved, even as the best features were obtained after 2 hours of artificial aging.
\end{abstract}

Keywords-heat treatment; Al alloy 6061 T6; mechanical properties

\section{INTRODUCTION}

The 6xxx group of $\mathrm{Al}$ alloys has received much research attention due to their great technological potential, as well as their exceptional strength enhancement following precipitation hardening. These alloys are commonly employed in the construction and automotive sector. The metastable precursors of the equilibrium phase are precipitated in a process that involves one or more complex sequences. Their chemical content, heat treatment parameters, and casting conditions greatly influence their extrudability and determine their microstructure. This implies that the properties of several aluminum alloys can be manipulated through specific heat treatment processes. The heat treatment can be executed either through solution heating ( $\mathrm{SH}$ ) or through artificial aging (AA). In the $\mathrm{SH}$ process, the alloy is heated to a temperature range of $400{ }^{\circ} \mathrm{C}-530^{\circ} \mathrm{C}$, before water quenching at ambient temperature, while AA or simply "hardening" is performed at about $200^{\circ} \mathrm{C}$ (in case of the group 6xxx of $\mathrm{Al}$ alloys). The temperature for age hardening usually ranges from $160^{\circ} \mathrm{C}$ to $200^{\circ} \mathrm{C}$ [1-3]. Aluminum alloys subjected to $\mathrm{SH}$ treatment are believed to have varying mechanical properties which account for their varying machinability. The stability and corrosion resistance of these materials can be improved by the addition of magnesium and silicon. Several mechanical properties exhibited by the $6 \mathrm{xxx}$ group of aluminum alloys are attributed to the type of treatment (solution, aging time and temperature) they are exposed to $[4,5]$.
The impact of heat treatment on the mechanical and microstructural features of alloys has been extensively studied. Authors in [1] investigated and reported the influence of precipitation hardening on the microstructural and mechanical attributes of 6xxx-group, 6061, 6063 and $6082 \mathrm{Al}$ alloys. The alloys were subjected to a 12-h heating in a furnace at a temperature of $565^{\circ} \mathrm{C}$ before being water quenched. The heated and cooled specimens were further exposed to AA for $98 \mathrm{~h}$ at $175^{\circ} \mathrm{C}$. The microstructural and mechanical properties of the studied samples were noted to be unaffected during AA as a result of the prior precipitation strengthening process. In [6], authors investigated the effect of combining different specified cold working and precipitation hardening procedures on the tensile strength of $6061 \mathrm{Al}$ alloy. The results showed that the application of a single AA process at $180^{\circ} \mathrm{C}$ for $4 \mathrm{~h}$ improved the strength of the studied specimens, while a double aging process had no influence on the mechanical features of the specimens. Additionally, the pre-aging process had a counteractive effect on the subsequent precipitation process on the material. These changes in the mechanical features of the specimens were attributed to the microstructural developments due to the conflicting influence of hardening by precipitation, work softening, and strain hardening processes on the samples. Authors in [7] studied the mechanical properties of the 6061T6 Al alloy at ambient temperature under various pre-thermal histories that represent an electron beam welding process. During the study, a fast-heating device was fabricated to deliver a controlled application of thermal loadings on the tensile samples. From the tensile tests conducted, it was observed that the yield stress decreased at RT when the optimum temperature limit was reached and when there was decrease in the heating rate. These differences in the mechanical properties were attributed to the microstructural changes that were evidenced by Transmission Electron Microscopy. Furthermore, authors in [8] studied the quench sensitivity of the mechanical properties of 6061 and $6069 \mathrm{Al}$ alloys by determining the relationship between quench delay time and the mechanical properties at varying temperatures in the range of $200^{\circ} \mathrm{C}$ to $500^{\circ} \mathrm{C}$. From the study, it was reported that the quench sensitivity of 6069-T6 was higher compared to that of 6061 , and this was attributed to the differences in their composition. The study also provided more information on the quench sensitivity of the conventional 6061 alloys. In the present study, our aim is to investigate the influence of AA time on the mechanical properties of Al $6061 \mathrm{~T} 6$ alloy. 


\section{EXPERIMENTAL WORK}

\section{A. Specimen Preparation}

Several specimens of the Al-6061 alloy were prepared for tensile strength test as shown in Figure 1 according to the recommendation of ASTM.176000.

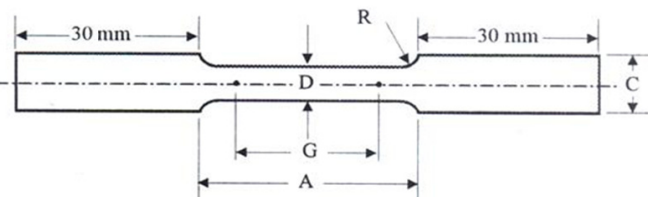

Fig. 1. Tensile test specimen

\section{B. Specimen Characterization}

The chemical content of the studied aluminum Al-6061 alloy was studied using an ARL spectrometer.

\section{Categorization of Specimens}

The specimens were categorized after preparation into several groups as presented in Table 1 .

TABLE I. CATEGORIZATION OF SPECIMENS

\begin{tabular}{|c|c|}
\hline Specimen category & Condition of specimen \\
\hline A & Base metal without treatment \\
\hline B & SHT for $500^{\circ} \mathrm{C}$ and AA for $1 \mathrm{~h}$ \\
\hline C & SHT for $500^{\circ} \mathrm{C}$ and AA for $2 \mathrm{~h}$ \\
\hline D & SHT for $500^{\circ} \mathrm{C}$ and AA for $3 \mathrm{~h}$ \\
\hline E & SHT for $500^{\circ} \mathrm{C}$ and AA for $4 \mathrm{~h}$ \\
\hline \multicolumn{2}{|c}{ Note: SHT $=$ solution heat treatment, AA $=$ artificial aging }
\end{tabular}

\section{Heat Treatment}

Solution heat treatments T6 and artificial aging were selected for the Al-6061 alloy. The as-received Al-6061 material was in $\mathrm{T} 6$ condition. It was heat-treated for $1 \mathrm{~h}$ at $500^{\circ} \mathrm{C}$ before being water quenched at room temperature, before re-heating to for $1,2,3$, and $4 \mathrm{~h}$ at $190^{\circ} \mathrm{C}$.

\section{E. Microstructure Examination}

An optical microscope was utilized to observe the changes in the microstructure of the base metal after heat-treatment. The specimens for microstructural analysis were prepared by grinding using SiC emery paper of grades $120,350,500$, and 800 . The samples were later polished with a cloth soaked in the $\mathrm{Al}_{2} \mathrm{O}_{3}$ solution. Furthermore, an etching process was performed on the specimens using Keller's reagent containing $95 \mathrm{~mL}$ of distilled water $+2.5 \mathrm{ml}$ of nitric acid $+1.5 \mathrm{ml}$ of hydrochloric acid $+1 \mathrm{~mL}$ of $\mathrm{HF})$

\section{F. Hardness Test}

A Vickers hardness testing machine was used to investigate the hardness property of the specimens, while the hardness values $(\mathrm{Hv})$ were calculated using the following equation:

$$
H v=1.854 \times \frac{p}{\left(d^{2}\right)}
$$

where $\mathrm{p}$ is theexerted load $(\mathrm{Kg})$ and $\mathrm{d}$ is the penetration diameter $(\mathrm{mm})$.

\section{G. Tensile Test}

The tensile strength of the specimens was determined at ambient temperature with the aid of an INSTRON 1125 tension machine. A load of $20 \mathrm{KN}$ was applied at a deformation rate of $2 \mathrm{~mm}$ per minute.

\section{H. X-Ray Diffraction (XRD)}

The XRD pattern of the specimens was determined at the Nano-Lab of the University of Technology, Baghdad, Iraq.

\section{RESULTS}

\section{A. Specimen Composition}

The chemical content of the studied Al-6061 alloy is presented in Table II.

TABLE II. CHEMICAL CONTENT OF AL-6061 (\% WT.)

\begin{tabular}{|c|c|c|}
\hline Elements w\% & Observed Value & Standard Value \\
\hline $\mathrm{Si}$ & 0.60 & $0.40-0.80$ \\
\hline $\mathrm{Fe}$ & 0.40 & Max 0.70 \\
\hline $\mathrm{Cu}$ & 0.30 & $0.150-0.40$ \\
\hline $\mathrm{Mn}$ & 0.120 & Max 0.150 \\
\hline $\mathrm{Mg}$ & 1.010 & $0.80-1.20$ \\
\hline $\mathrm{Cr}$ & 0.20 & $0.04-0.350$ \\
\hline $\mathrm{Zn}$ & 0.180 & Max 0.250 \\
\hline $\mathrm{Al}$ & Rem. & Rem. \\
\hline
\end{tabular}

\section{B. Microstructural Examination}

The microstructure of the samples is presented in Figure 2.

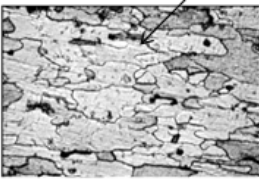

(A)

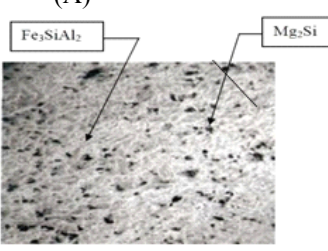

(D)

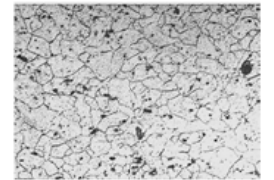

(B)

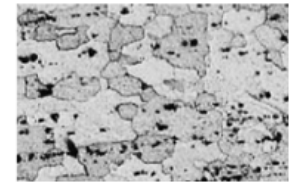

(C)
Fig. 2. Specimen's microstructure at $100 \mathrm{x}$

\section{Hardness Test}

Table III presents the observed hardness values of the Al6061 alloy.

D. Tensile Test

The tensile strength of the specimens, as determined using an INSTRON 1125 tension machine is presented in Table III.

TABLE III. MECHANICAL PROPERTIES OF THE SPECIMENS

\begin{tabular}{|c|c|c|c|c|c|}
\hline Category & A & B & C & D & E \\
\hline Ultimate Tensile Stress (MPa) & 332 & 387 & 432 & 342 & 336 \\
\hline Yield Stress (MPa) & 285 & 309 & 315 & 304 & 292 \\
\hline Elongation \% & 10 & 8 & 6 & 8.2 & 8.5 \\
\hline Hv Hardness (kg/mm $\mathbf{m}^{\mathbf{2}}$ ) & 95 & 118 & 121 & 117 & 110 \\
\hline
\end{tabular}




\section{E. XRD Test}

The XRD pattern of the examined specimens is shown in Figure 3.

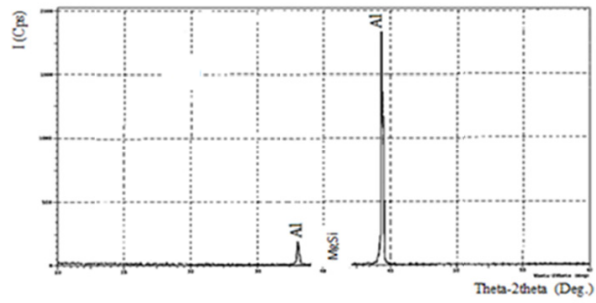

(A)

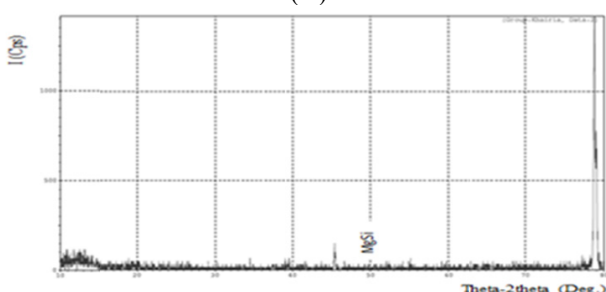

(B)

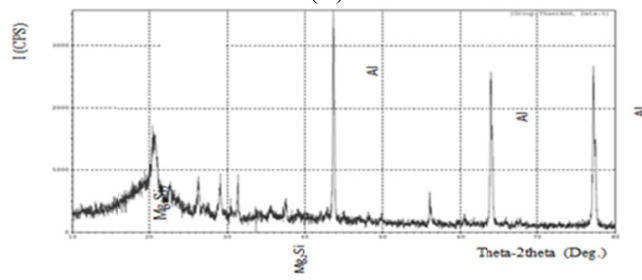

(C)

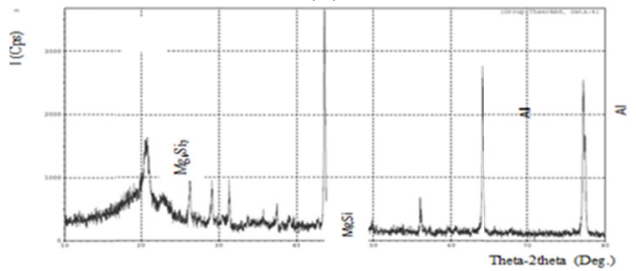

(D)

Fig. 3. X-ray phases of the specimens

\section{DISCUSSION}

The effect of AA time on the mechanical properties of 6061 T6 Al alloy was investigated in this report. The mechanical features of the examined alloys were found to be improved through the artificial aging process (Table III) compared to those of the base metal. It was observed that time of two hours gave the best strengthening likely due to the hard phases created by the magnesium and silicon elements (MgSi and $\left.\mathrm{Mg}_{6} \mathrm{Si}_{7}\right)$ which appeared clearly in the $\mathrm{X}$-ray diffraction patterns (Figure 3). The particles of those phases were uniformly distributed in the microstructure of the alloy after two hours, while their coarsening after three and four hours resulted in a reduction in the mechanical features of the samples compared to those after 2 hours (Figure 2). This finding agreed with previous reports $[9,10]$. Artificial aging at one hour (Specimen B) revealed less improvement on the strengthening of the specimen compared to those treated for two hours likely due to the microstructure of the $\alpha$ and $\beta$ phases. The $\beta$ phase in the internal structure of alloys is generally harder and less ductile than the $\alpha$ phase [1]. It is obvious from Table I that there was an improvement in the hardness of the alloy. The experienced hardening was attributed to the precipitation inherent in the material which hindered the dislocation glide. Hardening is most effective in the presence of smaller precipitates. The observed behaviors in this study are consistent with previous reports [11-13].

\section{CONCLUSION}

Aluminum 6061 alloys can be strengthened through a process of artificial aging within two hours. An increase in the hardness value of the 6061aluminum alloy of about $27.4 \%$ can be achieved through a 2-hour artificial aging process. An artificial aging time of more than two hours can decrease the strength and hardness of the material.

\section{REFERENCES}

[1] G. Mrówka-Nowotnik, "Influence of chemical composition variation and heat treatment on microstructure and mechanical properties of $6 \mathrm{xxx}$ alloys", Archives of Materials Science and Engineering, Vol. 46, No. 2, pp. 98-107, 2010

[2] N. R. Prabhu Swamy, C. S. Ramesh, T. Chandrashekar, "Effect of heat treatment on strength and abrasive wear behavior of Al6061-SiC p composites", Bulletin of Materials Science, Vol. 33, No. 1, pp. 49-54, 2010

[3] M. N. Hawas, "Effect of Ageing Time on Adhesive Wear of AL Alloy AA6061-T6", Journal of Kerbala University, Vol. 11, No. 4, pp. 145152,2013

[4] C. F. Tan, M. R. Said, "Effect of hardness test on precipitation hardening aluminum alloy 6061-T6", Chiang Mai Journal of Science, Vol. 36, No. 3, pp. 276-286, 2009

[5] H. Demir, S. Gunduz, "The effects of aging on machinability of 6061 aluminum alloy", Materials \& Design, Vol. 30, No. 5, pp. 1480-1483, 2009

[6] M. Mansourinejad, B. Mirzakhani, "Influence of sequence of cold working and aging treatment on mechanical behavior of 6061 aluminum alloy", Transactions of Nonferrous Metals Society of China, Vol. 22, No. 9, pp. 2072-2079, 2012

[7] D. Maisonnette, M. Suery, D. Nelias, P. Chaudet, T. Epicier, "Effects of heat treatments on the microstructure and mechanical properties of a 6061 aluminum alloy”, Materials Science and Engineering: A, Vol. 528, No. 6, pp. 2718-2724, 2011

[8] M. Kassner, P. Geantil, X. Li, "A Study of the Quench Sensitivity of 6061-T6 and 6069-T6 Aluminum Alloys", Journal of Metallurgy, Vol. 2011, Article ID 747198, 2011

[9] C. Ravi, C. Wolverton, "First-principles study of crystal structure and stability of Al-Mg-Si-(Cu) precipitate", Acta Materialia, Vol. 52, No. 14, pp. 4213-4227, 2004

[10] V. Massardier, T. Epicier, P. Merle, "Correlation between the microstructural evolution of a 6061 aluminum alloy and the evolution of its thermoelectric power", Acta Materialia, Vol. 48, No. 11, pp. 29112924, 2000

[11] M. Murayama, K. Hono, "Pre-precipitate clusters and precipitation processes in Al-Mg-Si alloys", Acta Materialia, Vol. 47, No. 5, pp. 1537-1548, 1999

[12] G. Edwards, K. Stiller, G. L. Dunlop, M. J. Couper, "The precipitation sequence in Al-Mg-Si alloys", Acta Materialia, Vol. 46, No. 11, pp. 3893-3904, 1998

[13] R. Ahmad, M. A. Bakar, "Effect of a post-weld heat treatment on the mechanical and microstructure properties of AA6061 joints welded by the gas metal arc welding cold metal transfer method", Materials \& Design, Vol. 32, No. 10, pp. 5120-5126, 2011 